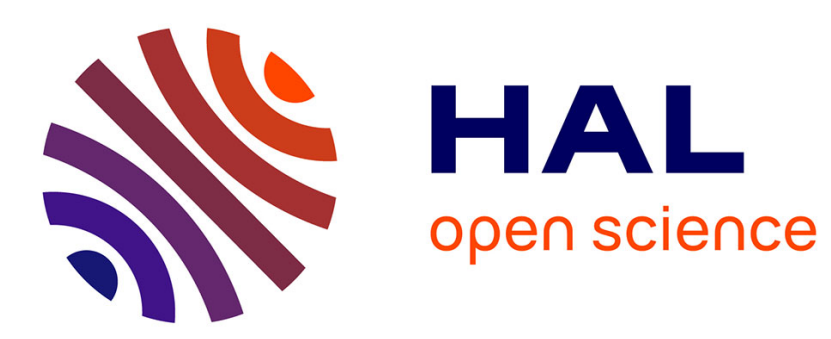

\title{
Plant metabolomics to the benefit of crop protection and growth stimulation
}

Cédric Bertrand, Azucena Gonzalez-Coloma, Claire Prigent-combaret

\section{To cite this version:}

Cédric Bertrand, Azucena Gonzalez-Coloma, Claire Prigent-combaret. Plant metabolomics to the benefit of crop protection and growth stimulation. Advances in Botanical Research, 98, Elsevier, pp.107-132, 2021, 10.1016/bs.abr.2020.11.002 . hal-03147015

\section{HAL Id: hal-03147015 \\ https://hal-univ-perp.archives-ouvertes.fr/hal-03147015}

Submitted on 17 Nov 2021

HAL is a multi-disciplinary open access archive for the deposit and dissemination of scientific research documents, whether they are published or not. The documents may come from teaching and research institutions in France or abroad, or from public or private research centers.
L'archive ouverte pluridisciplinaire HAL, est destinée au dépôt et à la diffusion de documents scientifiques de niveau recherche, publiés ou non, émanant des établissements d'enseignement et de recherche français ou étrangers, des laboratoires publics ou privés.

$$
\text { Copyright }
$$




\section{Plant metabolomics to the benefit of crop protection and growth stimulation}

\section{Cédric Bertrand $^{\mathrm{a}, \mathrm{b}, *}$, Azucena Gonzalez-Coloma ${ }^{\mathrm{c}, *}$, and Claire Prigent-Combaret ${ }^{\mathrm{d}}$}

${ }^{a}$ PSL Research University: EPHE-UPVD-CNRS, USR 3278. CRIOBE, Université de Perpignan,

Perpignan Cedex, France

'Société Akinao, Perpignan Cedex, France

${ }^{c}$ Instituto de Ciencias Agrarias, CSIC, Madrid, Spain

${ }^{\mathrm{d} U n i v e r s i t e ́ ~ L y o n, ~ U n i v e r s i t e ́ ~ C l a u d e ~ B e r n a r d ~ L y o n ~ 1, ~ C N R S, ~ I N R A, ~ V e t A g r o ~ S u p, ~ U M R ~} 5557$ Ecologie Microbienne, Villeurbanne, France

*Corresponding authors: e-mail address: cedric.bertrand@univ-perp.fr; azu@ica.csic.es

\section{Contents}

1. Introduction

2. Plant attraction/repulsion/defense processes are associated to chemical strategies: A playground for metabolomics

3. Volatilomics in plant-insect interactions, plant-plant dialogues and crop protection

3.1 Plant-insect interactions and VOCs

3.2 Plant-plant communication and VOCs

3.3 Direct effects on insects

3.4 Indirect effects on insects

3.5 Volatilomics and plant protection

4. Plant metabolomics applied to biostimulation and biocontrol products development

5. Metabolomics to understand and improve the mechanisms of perception and responses to the environment for health benefits

5.1 Impact of PGPR on primary metabolism of plants

5.2 Impact of bioproducts on the secondary metabolite profiles of plants

5.3 Plant and bacterial metabolomics to help the development of bioinoculants and multi-species consortia

6. Conclusion 


\section{Abstract}

Biotic and abiotic stresses strongly affect plant growth, quality of production and crop yield. Respectively biocontrol products and biostimulants have been proposed as agronomic tools to counteract those stresses. Research and development on biocontrol and biostimulant products require the study and characterization of the biotic and abiotic interactions involved in these processes. Plant metabolomics approach plays a key role in the identification of chemical mediators involved in these two types of interactions. Metabolomics is a useful tool for the characterization of volatile organic compounds (VOCs) involved in plant-insect interactions, or for the bioguided identification of active compounds from new raw materials. On the other hand, metabolomics approach can be used for the characterization of metabolic pathways affected by plant priming, biostimulant or elicitor application and/or for mechanistic study of Plant-PGPR (Plant Growth Promoting Rhizobacteria) interaction through biomarker specific metabolic fingerprint study.

\section{Introduction}

The success of modern-day intensive farming practices is often attributed to the use of agrochemicals. However, the development of these chemicals has led to many negative environmental and health consequences. Moreover, with the emergence of an increasingly frequent phenomenon of resistance among conventional pesticides and in a regulatory context for a use of pesticides better in line with sustainable development (EU pesticide package), the interest of manipulating metabolomics technologies in order to identify the plant's ability to interact metabolically/chemically with its environment and to identify levers that make it possible to implement solutions of protection and optimization of growth may lead to alternative solutions.

Plants interact with other organisms and particularity with other plants, insects and a large diversity of microorganisms that can be defined as the plant microbiota.

In one hand, some crude ethanolic or aqueous plant extracts are traditionally used by organic or biodynamic farmers for pests or microbial disease management, but relatively few studies exist regarding the effectiveness, standardization and composition of these extracts. On the other hand, the use of products from natural origin seems a sustainable option due to their perceived eco-friendly profile over environmentally harmful chemical pesticides. In this context, biocontrol products (Bps) are booming. Bps mostly include the use of microorganisms (viruses, bacteria and fungi) and botanical substances (essential oils, plant extracts, minerals, etc.) for biocontrol 
operations (Bertrand \& Prigent-Combaret, 2012). Botanical substances include pure natural compounds, plant extracts and botanical preparations. Except for pure compounds, one of the main intrinsic qualities of plant biobased products used for the development of biocontrol is the complexity of the preparation, as the mixture of metabolites could allow a high synergy of activity and avoid the development of pest resistance. In this context, traditional botanical preparations are getting increasing attention from the stakeholders (OECD, ENV/JM/M87MONO(2012)36). Nevertheless, the botanical ingredients being usually complex mixtures composed of several active ingredients, their composition needs to be characterized (Andreu et al., 2018), and metabolomics methods are well-adapted to best identify the composition of natural products.

Nowadays, plant metabolomics is increasingly useful in agrochemistry and in particular in biocontrol and development of alternative biobased solutions for crop protection or biostimulation. Metabolomics is also a useful tool for understanding plant-microorganism interactions and for the identification of bioactive compounds involved in those interactions that could lead to innovative biocontrol products.

Metabolomic tools are thus helpful for the development of biological control mainly to achieve the following different objectives: characterization of biomass; identification of active substances; characterization of complex mixture and characterization of biomarkers and mechanisms. This chapter deals with the subject of crop protection and biostimulation and the interest of manipulating metabolomic technologies in order to identify the plant's ability to chemically interact with its environment and to identify levers to implement solutions of protection and optimization of growth. It takes up concepts on plant metabolomics, chemical ecology, abiotic and biotic stress, and phytochemicals resources.

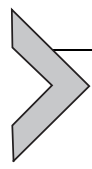

\section{Plant attraction/repulsion/defense processes are associated to chemical strategies: A playground for metabolomics}

All tissues of the plants (roots, stems, leaves and fruits) are associated to distinct microbial communities either at their surface (epiphyte) or inside the tissue (endophyte), the whole constituting the plant holobiont (Rosenberg \& Zilber-Rosenberg, 2016). Among the plant microbiota, some bacteria are able to promote plant development, using plant growth-promotion and plant protection properties. A large part of these microorganisms is associated 
to the plant roots that exude a wide variety of molecules within the rhizosphere. Exudates may represent between $20 \%$ and $50 \%$ of photosynthetic carbon produced by the plant and are able to attract and sustain the growth of a large diversity of microbial species (Haichar, Santaella, \& Heulin, 2014). In return, plant-beneficial microorganisms (also known as Plant Growth-Promoting Rhizobacteria, PGPR) are capable to promote the plant growth and protect plants against pathogens or abiotic stresses, thanks to several indirect or direct mechanisms (Vacheron et al., 2013). Among them, certain microorganisms will favor the growth of the plant using plant-beneficial functions such as nitrogen fixation, phosphate solubilization or even by modulating the plant hormonal pathways (via auxin production, deamination of 1-aminocyclopropane-1- carboxylate) (Drogue, Doré, Borland, Wisniewski-Dyé, \& Prigent-Combaret, 2012). Others have rather a plant protective activity and protect the plant against pathogens through three main mechanisms: competition, production of antimicrobial compounds, or induction of systemic resistance in the plant (Besset-Manzoni, Rieusset, Joly, Comte, \& Prigent-Combaret, 2018).

Regarding the use of these microorganisms in agriculture, plant-beneficial microorganisms or compounds they secrete can be used commercially to inoculate plants in order to stimulate their growth or protect them against diseases. They are in that case known as biostimulants and biocontrol products, respectively.

The European Biostimulants Industry Council (EBIC) have defined plant biostimulants as products "containing substance(s) and/or microorganisms whose function when applied to plants or the rhizosphere is to stimulate natural processes to enhance/benefit nutrient uptake, nutrient efficiency, tolerance to abiotic stress, and crop quality." (European Biostimulants Industry Council, 2012). This category regroups a wide diversity of biological and organic products including living microorganisms, algae products, animal or plant fermentation products, protein hydrolysates, composts and manures, food wastes, etc. (Brown \& Saa, 2015) but excludes mineral fertilizers. Biostimulants act by improving the plant nutrition and growth either directly by interacting with plant signaling cascades or indirectly through the stimulation of plant-beneficial microorganisms to produce molecules that will improve the plant nutrition and growth. Thus, biostimulant products are often containing high amounts of simple or complex carbohydrates that may act as a source of energy for plant-beneficial microorganisms or that may interact with plant signaling cascades. Bacteria of the genus Azospirillum is one of the most emblematic biostimulants of bacterial origin used in agriculture, 
particularly in South America, where members of this genus are often applied in fields to improve plant growth, with more than 100 products already in the market (Cassán et al., 2020). Many studies have shown that the application of microbe-based biostimulants benefits crops by a biostimulation process but it can also protect plants against biotic stresses, in which case the product can be used as a biocontrol product.

Biocontrol corresponds to a set of methods for protecting crops using living organisms or natural substances and natural mechanisms in the context of integrated pest management. Biological control is the most successful, most cost-effective and environmentally safest way of pest management. (IOBC Internet Book of Biological Control Version 6, Spring 2012 Copyright IOBC 1 IOBC Internet Book of Biological Control, version 6). Biological control or biocontrol and Biocontrol products development are also based on the knowledge of biotic interaction, and the characterization of the mechanisms of this interaction (Fig. 1). All those interactions are based on exchanges of metabolite (including volatiles) sometimes named allelochemical compounds or biomediators. It is now known that this allelochemicals exhibit high antifungal, anti-herbivory and antimicrobial properties or can have phytotoxic effects.

Bps are divided into four categories: macro-organisms, microorganisms, chemical mediators, and natural substances of animal or plant origins (Fig. 2). Macroorganisms include invertebrate organisms (insects, nematodes, mites) that have direct or indirect activity on pests. A distinction is made between predatory macro-organisms for which the pest is a prey (i.e., ladybugs against aphids) and parasitic macro-organisms for which the pest is an essential host for its development (trichogramma). Microorganisms (bacteria, fungi, viruses) have various activities (anti-insect, anthelmintic, antifungal, anti-bacterial, etc.). One hundred of bacterial strains have been registered as biocontrol agents around the world. In order of importance, they belong to Bacillus, Pseudomonas and Streptomyces genera (van Lenteren, Bolckmans, Köhl, Ravensberg, \& Urbaneja, 2018). Chemical mediators include insect pheromones and kairomones. Pheromones are signal molecules involved in the communication between insects of the same species, whereas kairomones are semio-chemical molecules released into the environment by producingorganisms to receptor organisms belonging to other species. Chemical mediators are used in two ways: biological control by trapping techniques or by mating disruption methods. Natural substances include all products of mineral, vegetable, animal or microbial origins. Their mechanisms of action are diverse. They are used against insects, bacteria, and fungi. This category is largely 


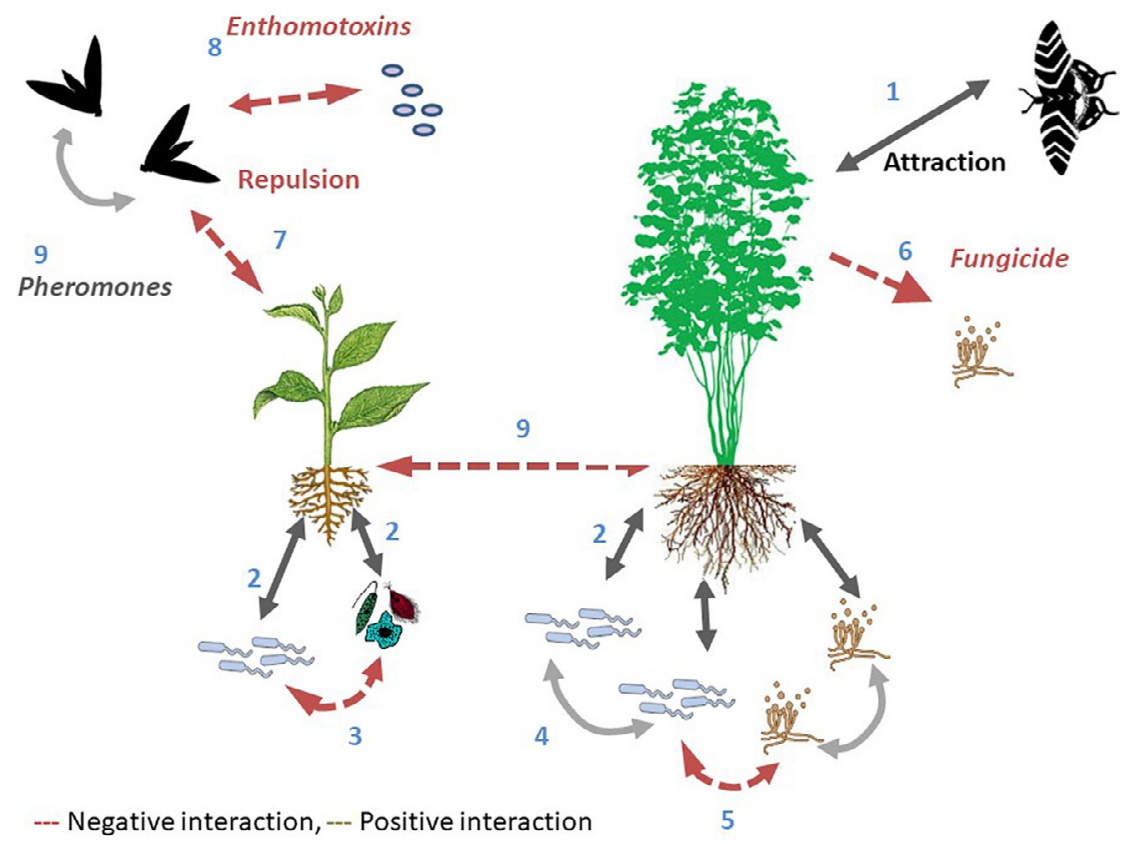

Fig. 1 Biotic interactions between organisms in plant systems: 1 -the plant emits large quantities of volatile compounds to attract pollinators but these compounds can also guide phytophagous insects. 2-Compounds emitted by the plant attract symbiotic but also phytopathogenic microorganisms. 3 and 5 Antibiosis: compounds emitted by certain microorganisms can inhibit other microorganisms. 4-In the context of a phenomenon called quorum sensing, certain compounds can be perceived within a population and induce a phase change, leading to the modification of the bacteria metabolism and, for example, to the production of virulence factors. 6-The plant is protected by the production of phytoalexins, antifungal or repellent compounds with respect to phytophagous organisms. 7-Compounds are emitted by the plant to repel biting sucking phytoagritic insects, it may be, for example, citronellol. 8-Entomopathogenic bacteria (e.g., Bacillus thuringiensis). 9-Phytotoxic compounds can also be produced by the plant to limit the growth of other plants, this is the phenomenon of allelopathy.

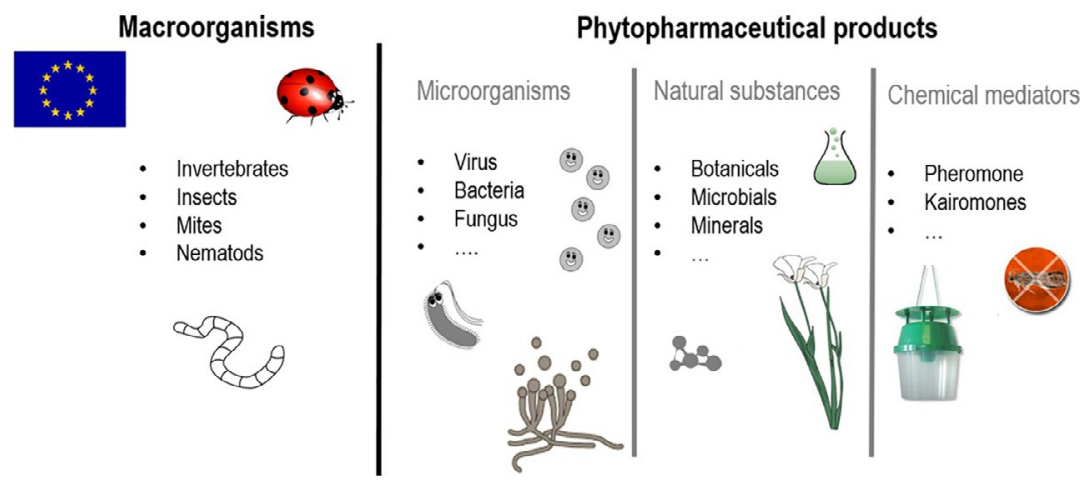

Fig. 2 Biocontrol products are agents and products that use natural mechanisms within the framework of integrated pest management. 
dominated by sulfur products and plant products. In addition to these product categories, there is also biocontrol by conservation, which aims to promote the action of auxiliary organisms already present in the environment, and biocontrol by acclimatization, which aims to obtain a permanent establishment of an exotic auxiliary organism to regulate the populations of an invasive species.

Plant metabolomics is increasingly useful in agrochemistry and in particular in biocontrol and development of alternative biobased solutions for crop protection or biostimulation. Metabolomics enables to better understand plant-microorganisms' interactions and makes possible the identification of bioactive compounds involved in those interactions.

\section{Volatilomics in plant-insect interactions, plant-plant dialogues and crop protection}

The plant volatilome includes volatile essential oil components and volatile organic compounds (VOCs) (Kantsa, Sotiropoulou, Vaitis, \& Petanidou, 2015). VOCs are biosynthesized from the mevalonic acid and methylerythritol phosphate pathways (isoprenoids), the lipoxygenase pathway (fatty acid derivatives), the shikimic acid pathway (benzenoids and phenylpropanoids), the amino acid derivatives pathway (Baldwin, 2010; Conchou et al., 2019) and other metabolic routes giving alkenes and small oxygenated compounds (ethylene acetaldehyde, acetone, methanol) (Jardine et al., 2017). The release of these substances is frequently associated with biotic and abiotic stresses that include herbivory by insects (Arimura \& Pearse, 2017).

VOC emissions vary within species (Vivaldo, Masi, Taiti, Caldarelli, \& Mancuso, 2017), with environmental conditions (including above or below ground interactions) (Delory, Delaplace, Fauconnier, \& du Jardin, 2016), and within individual plants depending on the organs. For example, pinene emissions from maritime pine branches or stems are composed of different enantiomers (Staudt, Byron, Piquemal, \& Williams, 2019). Plant-associated microorganisms such as epiphytic (Helletsburger, Dötterl, Ruprecht, \& Junker, 2017) or endophytic bacteria (Maggini et al., 2019) can significantly affect the VOC composition released by a plant organ.

\subsection{Plant-insect interactions and VOCs}

Plants release VOCs as a response to insect attack (Holopainen \& Gershenzon, 2010). Herbivore-induced plant volatiles consist mainly of terpenes, green leaf volatiles, phenylpropanoids and plant signals (Fig. 3). 


\section{Phenyl propanoids}<smiles>COC(=O)c1ccccc1O</smiles><smiles>O=Cc1ccccc1</smiles><smiles>O=CCc1ccccc1</smiles>

$\mathrm{HO}$

Methyl salicylate Benzaldehyde 2-Phenylethanol

Phenylacetaldehyde

Eugenol

Green Leaf Volatiles<smiles>CCC/C=C/C=O</smiles>

(E)-2-Hexenal<smiles>CC/C=C\CC=O</smiles>

(Z)-3-Hexenal<smiles>CC/C=C\CCO</smiles>

(Z)-3-Hexenol<smiles>CC/C=C\CCOC(C)=O</smiles>

(Z)-3-Hexenyl acetate

Monoterpenes<smiles>C=CC(C)=CCC=C(C)C</smiles>

$\beta$-Ocimene

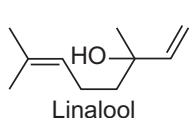

Linalool

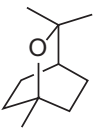

1,8-Cineole

Homoterpenes<smiles>C=C/C=C(\C)CCC=C(C)C</smiles>

(E)-4,8-Dimethyl-1,3,7-nonatriene (DMNT)<smiles>C=C/C=C(\C)CC/C=C(\C)CCC=C(C)C</smiles>

(E,E)-4,8,12-trimethyl-1,3,7,11-tridecatetraene (TMTT)<smiles>C=C(CC)CC/C=C(\C)CCC=C(C)C</smiles>

(E)- $\beta$-Farnesene

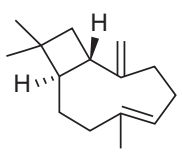

$\beta$-Caryophyllene
Glucosinolates<smiles>C=CC/C(=N/OS(=O)(=O)O)SC1O[C@H](CO)[C@@H](O)[C@H](O)[C@H]1O</smiles>

Cyanogenic glycosides<smiles>CC/C=C\CC1C(=O)CCC1CC(=O)OC</smiles>

Methyl jasmonate<smiles>OC[C@H]1O[C@@H](OC[C@H]2O[C@@H](OCc3ccccc3)[C@H](O)[C@@H](O)[C@H]2O)[C@H](O)[C@@H](O)[C@@H]1O</smiles>

Amygdalin

Fig. 3 Main volatile organic compounds involved in plant-insect interactions. 
Jasmonic acid (JA) is a herbivore-related plant defense signal. JA regulates the emission of herbivore-induced VOCs, mostly terpenes (Paudel Timilsena, Seidl-Adams, \& Tumlinson, 2020). Other signaling molecules, such as ethylene and salicylic acid, act synergistically with JAs to regulate the biosynthesis of VOCs and other herbivore-induced plant defenses (Okada, Abe, \& Arimura, 2015). These responses are highly specific to the herbivore species and ecology. Spodoptera exigua, Mythimna separata, or Tetranychus urticae induced different mixtures by feeding on lima bean plants (Arimura \& Pearse, 2017). The specialist Manduca sexta induced the production of jasmonic acid and ethylene when feeding on Nicotiana attenuata, while the generalist Spodoptera litura induced salicylic acid (Paudel Timilsena et al., 2020). JAs do not fully explain how plants induce herbivore-specific VOC mixtures. Elicitor molecules from the herbivore saliva could regulate the JAs signaling pathway (Arimura \& Pearse, 2017).

Terpenes are the most structurally diverse chemical group, originated by the terpene synthase family of enzymes. The structural diversity of aromatic compounds and phenylpropanoids comes from the action of methyl and acetyltransferases and includes $\mathrm{C6} / \mathrm{C} 1$ (methyl salicylate, benzaldehyde), C6/C2 (2-phenylethanol, phenylacetaldehyde) and C6/C3 (eugenol, chavicol) subclasses. Green leaf volatiles originate from lipid oxidation through the lipoxygenase pathway and are the major volatiles in terrestrial plants, mostly composed of (Z)-3-hexenal, (E)-2-hexenal, $(Z)$-3-hexen1-ol and (Z)-3- hexen-1-yl acetate (Arimura \& Pearse, 2017).

Additionally, essential oils in aromatic plants, glucosinolates in Brassicaceae, cyanogenic glycosides in Rosaceae and oleoresins in conifers, are released after herbivore attacks due to physical damage of the storage tissues (Arimura \& Pearse, 2017). Essential oils and oleoresins are mainly composed of terpenes (mono- and sesquiterpenes) and play a role in attracting natural herbivore enemies, protection against pathogens, plant to plant signaling and attracting pollinators among others (Sharifi-Rad et al., 2017). Glucosinolates are glycosylated secondary metabolites present in Brassicaceae. They contain a $\beta$-D-glucose moiety linked to a $(Z)-N$-hydroximinosulfate ester with an amino acid-derived side chain (Jeschke, Gershenzon, \& Vassão, 2016; Kumar, 2017). The enzymes myrosinases transform glucosinolates to volatile toxic isothiocyanates after plant damage and are stored in myrosin cells in the phloem parenchyma and stomata guard cells (Kumar, 2017). Cyanogenic glycosides are glycosidic derivatives of $\alpha$-hydroxynitriles stored in vacuoles separated from the $\beta$-glucosidases that hydrolyze them after tissue damage, releasing HCN, a potent toxin (Kumar, 2017; Zagrobelny, de Castro, Møller, \& Bak, 2018). 


\subsection{Plant-plant communication and VOCs}

VOCs can induce systemic VOCs by de novo synthesis in damaged or undamaged tissues (Holopainen \& Gershenzon, 2010). This type of signaling has been described in hybrid poplar (Populus deltoides $\mathrm{x}$ nigra) damaged by gypsi moth (Lymantria dispar) larvae, in lima bean leaves damage by beetles (Cerotoma ruficornis and Gynandrobrotica guerreroensis) inducing the production of extrafloral nectar in adjacent leaves and in sagebrush and willow which VOCs induced defenses in clonal plants (Karban, Shiojiri, \& Ishizaki, 2010; Pearse, Hughes, Shiojiri, Ishizaki, \& Karban, 2013). Inter-branch communication has been shown in blueberry plants attacked by gypsy moth (Rodriguez-Saona, Rodriguez-Saona, \& Frost, 2009). Insect herbivore feeding also modified the concentrations and the distribution of total and individual glucosinolates in the plant (Kumar, 2017).

VOCs can also prime plants, allowing for greater responses after a subsequent herbivory attack (Ali, Sugimoto, Ramadan, \& Arimura, 2013; Holopainen \& Gershenzon, 2010). Herbivore-induced indole primed mono and homoterpenes and the production of stress hormones (jasmonateisoleucine conjugate and abscisic acid) in neighboring maize plants (Erb et al., 2015). There is no clear evidence on how species-specific is the priming effect. The generalist Heliothis virescens or the specialist Manduca sexta induced VOCs that primed the production of defensive volatiles and JA in Nicotiana benthamiana by a conspecific regurgitant (Paudel Timilsena et al., 2020). Other reports showed herbivore-specific induction of defense priming. The reproductive rate of a specialist or generalist aphid (Uroleucon macolai, Aphis gossypii) in Baccharis salicifolia plants was significantly reduced when primed plants were damaged by the same aphid species (Moreira, Nell, Katsanis, Rasmann, \& Mooney, 2018). Furthermore, whitefly modified the composition of VOC emissions by tomato plants by mimicking a pathogen attack that increased the quality as hosts for the insect in neighboring plants (Zhang et al., 2019).

Other VOCs such as essential oils can also prime plant defenses. Thyme essential oil primed defense responses in apple fruit against the fungal pathogen Botryitis cinerea through the PR-8 gene of apple (Banani et al., 2018), however little is known on their priming for insect defenses.

\subsection{Direct effects on insects}

Many reports on herbivore-plant interactions mediated by induced VOCs showed attraction. (E)-4,8-Dimethyl-1,3,7-nonatriene was identified as an 
attractant to fall armyworm (Spodoptera frugiperda) in VOCs released by cowpea plants after insect infestation (Takabayashi \& Shiojiri, 2019).

Volatile terpenes or green leaf volatiles deter oviposition of insect species (Holopainen \& Gershenzon, 2010; Papanastasiou, Ioannou, \& Papadopoulos, 2020). Aphids and thrips are repelled by volatile terpenes (Avellaneda, Díaz, Coy-Barrera, Rodríguez, \& Osorio, 2019; Li et al., 2019) and green leaf volatiles (Ahmed et al., 2018). Furthermore, there are many examples in the literature on the direct repellent, antifeedant and insecticidal effects of essential oils and their components (Ikbal \& Pavela, 2019; Pavela \& Benelli, 2016).

Glucosinolates hydrolyzed by myrosinases after tissue damage give unstable aglucones that degrade to isothiocyanates, which are direct defenses against herbivores (Jeschke et al., 2016) and stimulate larval feeding, oviposition and host location by specialist feeders (Kumar, 2017). Plant cyanogenic glycosides stored in the vacuole are hydrolyzed upon tissue damage by specific cyanogenic $\beta$-glucosidases to the corresponding $\alpha$-hydroxynitriles which release toxic HCN (Morant et al., 2008).

\subsection{Indirect effects on insects}

VOCs attract herbivore predators and parasitoids after above and below ground herbivore oviposition and/or feeding. Tests with VOCs and transgenic plants allowed for the identification of specific terpenes and green leaf volatiles involved in enemy attraction (Holopainen \& Gershenzon, 2010). The parasitoid wasp of Pieris rapae larvae (Cotesia glomerata) is attracted to (E)-3hexenal and (Z)-3-hexenyl acetate. The parasitoid of Plutella xylostella larvae (C. vestalis) is attracted to a mixture of four volatiles [(Z)-3-hexenyl acetate, $\alpha$-pinene, sabinene, and n-heptanal]. VOCs induced by Tetranychus urticae attract their predatory mites Phytoseiulus persimilis. Lady beetles use different willow VOC mixtures to find prey patches (Takabayashi \& Shiojiri, 2019).

Glucosinolates and their breakdown products have distinct roles in multitrophic interactions. Parasitoids of Brassicaceae specialist herbivores find their hosts using isothiocyanates (Kumar, 2017). Myrosinase activity has been detected in insects that can sequester glucosinolates from their food plants (the aphids Lipaphis erysimi, Brevicoryne brassicae and in the flea beetle Phyllotreta striolata). Upon attack by a predator, isothiocyanates are released, deter predators and are also synergists of the aphid alarm pheromone (E)- $\beta$-farnesene (Beran, Köllner, Gershenzon, \& Tholl, 2019).

Cyanogenic glycosides are also a defense system against enemies. Larvae of the burnet moth (Zygaena filipendulae) sequester bitter linamarin and 
lotaustralin and the release of toxic HCN after their breakdown deter enemies (Beran et al., 2019).

\subsection{Volatilomics and plant protection}

The importance of the plant volatilome on plant-insect interactions has practical implications in plant protection. The introduction of VOC releasing plant species in a crop can reduce pest damage (Conchou et al., 2019). As previously mentioned VOCs can reduce oviposition, including non-host volatiles. Methylsalicylate emitted by birch trees affects mating of the processionary moth affecting nearby pines (Jactel, Birgersson, Andersson, \& Schlyter, 2011). This can be used in push-pull strategies (Conchou et al., 2019).

The study of plant volatilomics requires gas chromatography (GC) coupled with mass spectrometry (GC-MS) (Bicchi \& Maei, 2012). Hydrodistillation is a limited extraction technique used for essential oils from aromatic plants. The most common method for efficient extraction of VOCs is the use of Solid Phase Microextraction (SPME), based on the absorption-adsorption of the head-space volatiles into a coated fiber (Boiteux et al., 2018). This technique allows for the study of biogenic VOCs (Wong, Yan, Shellie, Sciarrone, \& Marriott, 2019).

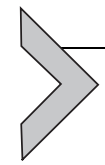

\section{Plant metabolomics applied to biostimulation and biocontrol products development}

Throughout the globe approximately 2 million tonnes of pesticides are utilized, out of which $47.5 \%$ are herbicides, $29.5 \%$ are insecticides, $17.5 \%$ are fungicides and 5.5\% are other pesticides (Sharma et al., 2019). In this context research of alternative to synthetic herbicides is a priority. Among the options for developing alternatives to synthetic herbicides, exploring the diversity of allelochemical compounds and simultaneously identifying sources of biomass supply or proposing a green chemical synthesis of the natural pure compounds could be a valuable option.

Securing high quality biomass is the basic condition for any development plants-based biocontrol products. As an example, citral would be a good candidate for bioherbicide development. Citral is a monoterpene commonly found as volatile component in many different aromatic plants. It has shown a high herbicidal effect on weeds (Graña, Sotelo, Díaz-Tielas, Reigosa, \& Sánchez-Moreiras, 2013). Elionurus muticus is a grass from Pampa biome, Brazil known as lemongrass and is considered as an alternative source of citral. This species has been considered to have a large economically important 
potential among the main essential oils that are produced from grass (Füller, Bertrand, Simon, de Barros, \& Neto, 2014). At the very beginning, chemical characterization of wild populations of E. muticus was needed. Several plants samples four different from four different populations were collected in southern Brazil. Metabolic profiling was performed using gas chromatography and mass spectrometry. The results showed that the studied populations have chemical variability based on their geographic origin, which indicates the possibility of chemotypes (Füller et al., 2017).

Based on the results of this first metabolomic approach, the cluster constituted with the plants collected from Morro Santa and Sao Borja would be selected, because of a high quantity of citral and stable quality of the essential oil. This "chemotype" could be a good candidate for the development of a bioherbicide.

Some traditional plants used for plant protection are nowadays commercialized within the framework of the EU regulation as Basic substances. Basic substances are substances that are not predominantly used for plant protection purposes but are useful in plant protection. Further criteria according to article 23 of Regulation (EC) No 1107/2009 are that they are not substances of concern, that they do not have the capacity to cause endocrinedisrupting, neurotoxic or immunotoxic effects, and that they are not placed on the market as plant protection products. Some crude aqueous extracts of those basics' substances are traditionally used by organic or biodynamic farmers for pests or microbial disease management, but relatively few studies exist, on the effectiveness of these extracts (Andreu et al., 2018). For example, white willow (Salix alba) bark, horsetail (Equisetum arvense), Urtica spp. are used in organic farming for various claimed activities. These plants are commonly used within aqueous decoction or maceration, and the observed variability in activity in the field has been widely described. One of the supposed causes of this is variability is non-standardized preparation workflows or poor quality of the plant. For the first point EU regulation proposes a "Mode of use" (e.g., Basic Substance, Equisetum arvense L. SANCO/ 12386/2013-rev. 720 July 2017) for each approved basic substance. Regarding plant quality assessment metabolic profiling could be used for the identification and characterization of the potential mixtures of bioactives metabolites and/or quality biomarkers. Salix alba cortex has been shown to have antifungal activity against Plasmopara viticola (Andreu et al., 2018; Deniau et al., 2019). In vitro assays have shown willow bark extracts have a potential anti-germinative effect on spore of Plasmopara viticola. This antigerminative activity of Salix alba cortex extract would be related with the 
high amount and the diversity of the polyphenol characterized by HPLCDAD-MS/MS-based metabolomic profiling (Andreu et al., 2018).

We have shown that M. gale fruits and leaves extracts exhibit phytotoxic activities against different plant species, including against the invasive species Fallopia (Popovici et al., 2011). The phytotoxicity is due to the presence of 3-(1-oxo-3-phenylpropyl)-1,1,5-trimethylcyclohexane-2,4,6-trione (myrigalone A), a dihydrochalcone present in both the fruits and leaves. We hypothesize that $M$. gale could be used in the future to being a potential source of environmentally friendly herbicides. Identification of the active metabolite (Myrigalone A) was reached within a classical bioguided fractionation workflow following by dereplication procedure combining uses of spectral properties of targeted metabolite (Popovici et al., 2011; Popovici, Bertrand, \& Comte, 2009). This last method is now judged to be inadequate in terms of time and cost, particularly in case of screening of new raw materials as micro-mycetes, bacteria or micro-algae. For this purpose, new metabolomic workflows are emerging usually: a rapid micro-fractionation of crude extracts is carried out followed by multivariate data analysis of their UPLC-HRMS/MS profiles. In parallel bioactivity of crude extracts and micro-fractionation of each active crude extract are evaluated. For example, herbicide potential can be evaluated based on the inhibition of plants specifics enzymes using microtiter plate screening systems. Mass spectral similarity networking is used to highlight clusters involved in the evaluated activity.

\section{Metabolomics to understand and improve the mechanisms of perception and responses to the environment for health benefits}

During their growth, plants interact with a huge diversity of microorganisms. These biotic interactions are mediated by a very wide variety of secondary metabolites produced either by PGPR, other members of the soil microbial community and by the plant (Moco et al., 2007; Venturi \& Keel, 2016). Indeed, both plant and microbial metabolomics studies are key methods to better understand the molecular dialogue established when plants are interacting with biocontrol or biostimulant PGPR. After the perception of PGPR through their cell surface components (i.e., flagella, lipopolysaccharides; Jourdan, Ongena, \& Thonart, 2008; Ramamoorthy, Viswanathan, Raguchander, Prakasam, \& Samiyappan, 2001), plants respond, among others, by modulating their metabolic pathways. Several studies have reported that 
primary and secondary metabolite profiles in roots, shoots and xylem sap were modified upon inoculation of PGPR (Chamam et al., 2013; Mishra, Singh, Jaiswal, Kumar, \& Maurya, 2006; Osbourn, Qi, Townsend, \& Qin, 2003; Rozier et al., 2016; Walker et al., 2011).

\subsection{Impact of PGPR on primary metabolism of plants}

Several studies evidence that PGPR are able to modify the primary metabolism of plants and in particular the pool of carbon compounds in plants at both above and below ground (Lade et al., 2018). This results in the alteration of root exudation patterns upon Azospirillum inoculation with an increase of organic compounds and sugars potentially exudated by roots (Rozier et al., 2016). Pseudomonas strains are also able to modify plant root exudates (Kuzmicheva et al., 2017; Matilla et al., 2010).

Metabolic contents of xylem sap of maize inoculated by the biostimulant A. lipoferum CRT1 was analyzed (Rozier et al., 2016). Xylem sap contains a wide range of small, water-soluble, organic substances such as primary metabolites (sugars, amino acids, organic acids, etc.). A. lipoferum triggers decrease of primary metabolite contents in the xylem sap, and release of metabolites outside of the roots as root exudates (Rozier et al., 2016). It is therefore hypothesized that PGPR increases the flux of metabolites from the interior to the exterior of roots to favor the PGPR growth. Shikimic acid (lignin precursor) and quinic acid content also decrease in xylem sap after Azospirillum inoculation. This may be due to the potential sequestration of phenylproponoids in roots and the modification of the lignin content in maize (Chamam et al., 2013; El Zemrany et al., 2006).

A. brasilense $\mathrm{Sp} 7$ was recently shown to interact differently with tomato and maize, used as models of $\mathrm{C}_{3^{-}}$and $\mathrm{C}_{4}$-host plants, respectively (Lade et al., 2018). In tomato, the Azospirillum strain induces higher stress responses with the production of reactive oxygen species (ROS) and higher damages of photosynthetic proteins than in maize, where the photosynthetic apparatus appears much more protected. This leads to a better interaction of the PGPR and plant growth with inoculated maize compared to inoculated-tomato.

\subsection{Impact of bioproducts on the secondary metabolite profiles of plants}

The inoculation of cereals (maize, rice, wheat) by Azospirillum lipoferum and $A$. brasilense strains leads to variable modifications of the secondary metabolism 
of the plant partner, depending on bacterial strain-plant species or plant cultivar combinations, suggesting strain-dependent responses (Walker et al., 2011).

In rice, secondary metabolite profiling revealed that Azospirillum inoculation significantly affected hydroxycinnamic acid (HCA), hydroxycinnamic acid amides (HCAA), resorcinol derivatives and flavonoids content in a strain-dependent manner (Chamam et al., 2013; Valette, Rey, Gerin, Comte, \& Wisniewski-Dyé, 2020). In maize, the metabolites, whose contents are modified in response to the inoculation of Azospirillum, are mainly benzoxazoninones and benzoxazolinones (Walker et al., 2011). To date, these compounds have been identified in many Poaceae such as corn, wheat and rye. It is important to note that major secondary metabolism changes could arise without morphological effects on root architecture, indicating that PGPR can affect plant secondary metabolism without influencing the physiological functions linked to plant growth (Chamam et al., 2013; Rozier et al., 2016; Walker et al., 2011).

To analyze better the specificity of PGPR-plant interaction, the effects of two strains of Azospirillum sp. B510 and A. lipoferum 4B on the secondary metabolism of two rice cultivars were compared (Chamam et al., 2013). Modulation of the metabolic profiles of the two cultivars in the presence of the strain B510, and only one cultivar in the presence of the strain 4B. In this case, the cultivar corresponds to the cultivar from which the $4 \mathrm{~B}$ strain was originally isolated. Moreover, the strongest plant phytostimulatory responses were observed when each strain was inoculated onto its host cultivar (Chamam et al., 2013). Furthermore, the positive plant growth responses are combined to the reduced expression of genes involved in stress responses and plant defense (Drogue et al., 2014). This result suggests that co-evolution between a host plant and a PGPR may result in attenuation of plant defense reactions.

The Azospirillum sp. B510 is able to colonize the interior of the tissues of the two rice cultivars thanks to its ability to produce a set of pectinolytic and cellulolytic enzymes promoting the degradation of plant walls and its entry into plant tissues (Boyer, Bally, Perrotto, Chaintreuil, \& Wisniewski-Dyé, 2008). Although it is a plant-beneficial bacteria, during the first stages of the interaction, the plant response to this PGPR has strong similarities to that induced by the pathogen Burkholderia glumae (Chamam, Wisniewski-Dyé, Comte, Bertrand, \& Prigent-Combaret, 2015). Among the discriminant compounds, $p$-coumaric acid, feruloyl-quinic acid and feruloyl hexoses have been identified in rice (mainly the cultivar Cigalon) as being induced in the 
presence of the pathogen and the endophytic PGPR B510. C-glycosylated flavones are other discriminating phenolic compounds induced in the presence of the pathogen and the endophytic PGPR. All these compounds have been described as having antioxidant or antimicrobial activities (BrazierHicks et al., 2009; Qiu, Liu, \& Beta, 2009), or as being intermediates in the biosynthesis of lignin for feruloyl-quinic acid and feruloyl hexoses (Vanholme, De Meester, Ralph, \& Boerjan, 2019).

In a wider study where the Nipponbare cultivar was inoculated with several Azospirillum strains initially isolated from rice or other plants and other PGPR not belonging to the Azospirillum genus, like Paraburkholderia phytofirmans and Herbaspirillum seropedicae, it was shown that some common plant metabolic signature could be however observed between all the studied strains (Valette et al., 2020). Three compounds that exhibit the greatest accumulation in response to all PGPR have been identified as HCA derivatives: feruloyl quinic acid, $\mathrm{N}$-p-coumaroylputrescine and $\mathrm{N}$-feruloylputrescine, the two latter being HCA amides (HCAA). Contrarily, when the rice was inoculated with a pathogen $B$. glumae the $\mathrm{N}$-feruloylputrescine content appeared to be 11-fold reduced compared to the control condition. However, the main role of HCAA reported in the literature concerns the protection of the plant against abiotic and biotic stresses, some HCAA being associated with antimicrobial properties (Bassard, Ullmann, Bernier, \& Werck-Reichhart, 2010). Six compounds exhibited a lower accumulation in response to inoculation by all the PGPR. Among them, three have been identified as resorcinol derivatives (Valette et al., 2020).

Among biocontrol mechanisms controlling crop diseases, using induced resistance is a real challenge for pesticide-free agriculture development. Biological inducer (i.e., PGPR, fungi or plant and algal extracts) are widely reported to induce resistance against a broad spectrum of pathogens in many plant species. An important consideration when using induced resistance is the crop plant itself. Different varieties of a crop plant can exhibit marked differences in the expression of induced resistance. It is possible that induced resistance might not be appropriate for use in some crops, especially if research shows the crop to be poor at responding to elicitor (Walters, Ratsep, \& Havis, 2013). It is necessary to evaluate the efficiency of the elicitor according to plant species and stress conditions. In this context, elucidation of the plant metabolic responses that occur after elicitation would help develop strategies based on natural defense stimulation. Study of elicitation within NMR technique applied on leaves of grape wine was found to be relevant as it covers a wide range of the plant metabolome (Burdziej et al., 2019). 
LCMS profiling would be also suitable for elicitation characterization of a wide range of plant, white radish (Rakpenthai, Khaksar, Burow, Olsen, \& Sirikantaramas, 2019), Medicago truncatula (Broeckling et al., 2005), wheat (Gawlik-Dziki et al., 2016). Plant metabolomics would be an appropriate tool for evaluating elicitation efficiency depending on plant species, variety, and environmental stress.

\subsection{Plant and bacterial metabolomics to help the development of bioinoculants and multi-species consortia}

Bioinoculant products have been for a long time composed of only one microorganism. Several studies had stressed the positive impact of multi-species consortia on plant growth, plant health and plant physiology (Besset-Manzoni et al., 2018). By combining microorganisms with different plant-beneficial functions one can expect better effects on the plant due to synergistic effects of the microorganisms rather than when one plant-beneficial microorganism is inoculated.

The impact of multi-species bioinoculants on plant growth was studied as early as 1995 with Azospirillum and Arthrobacter strains used as nitrogen fixers, and Agrobacterium as a phosphate-solubilizing bacterium (Belimov, Kojemiakov, \& Chuvarliyeva, 1995). Indeed, inoculation of barley with the consortium allowed increased nitrogen and phosphate plant uptakes, compared to single inoculations. In other studies, the inoculation of mycorrhizal fungi with bacteria was shown to promote plant growth (Kim et al., 2010; Wu, Cao, Li, Cheung, \& Wong, 2005). Consortia were also shown to better protect plants against abiotic stress or pathogens than individual strains (Sarma, Yadav, Singh, \& Singh, 2015; Vurukonda, Vardharajula, \& Shrivastava, 2016).

The molecular mechanisms of interactions between consortium's microorganisms leading to additive or synergistic effects on the plants are often not investigated. The interaction of antagonistic biocontrol DAPG-producing Pseudomonas and biostimulant Azospirillum brasilense deserves particular attention because of the growth-inhibiting activity of Pseudomonas antimicrobial metabolites, such as 2,4-diacetylphloroglucinol against Azospirillum (Couillerot et al., 2011). However, synergistic effects might also exist since DAPG has been shown to increase, at low molecular concentrations the expression of genes encoding plant-beneficial-functions in $A$. brasilense, like the $p p d C$ gene required for the biosynthesis of the auxin acid indole-3-acetic acid (Combes-Meynet, Pothier, Moënne-Loccoz, \& Prigent-Combaret, 2011). In addition, the two strains were shown to grow better when they 
are co-cultivated in mixed biofilms (Pagnussat et al., 2016). Biofilms correspond to bacterial populations adhering to each other and/or to surfaces and enclosed in an extracellular polysaccharide matrix, and where the exchange of metabolites between bacteria is particularly favored. Thanks to an untargeted bacterial metabolomic analysis, Rieusset and collaborators evidenced that biocontrol Pseudomonas strains produced a higher and more diversified content of secondary metabolites in biofilms than in planktonic lifestyle (Rieusset et al., 2020). The increased production of secondary metabolites in biofilms will influence the biotic interactions of fluorescent Pseudomonas with their host plant and with other members of the rhizomicrobiota. Promoting biofilm formation when developing bioinoculants might thus help to enhance their biocontrol or biostimulant activities. Similar observations have also been made with plant-associated Bacillus strains that overproduce antimicrobial compounds in biofilms with the up-regulation at a transcriptional level of $f e n A$ involved in the synthesis of the antifungal cyclic lipopeptide, fengycin; $b m y A$, involved in the synthesis of the antifungal compound, bacillomycin D; and $d h b A$, involved in the synthesis of the siderophore, bacillibactin (Pandin et al., 2019). Furthermore, the production of Bacillus bioactive secondary metabolites and developmental processes like biofilm formation and sporulation are modified upon biotic interactions of bacilli PGPR with rhizosphere-inhabiting competitors or fungal pathogens (Andrić, Meyer, \& Ongena, 2020).

Currently, there is great enthusiasm for the design and study of synthetic communities (SynCom) of rhizosphere microorganisms. Plant-inoculated SynCom should be comprised of multi-species populations possessing complementary modes of actions on plants (Liu, Qin, \& Bai, 2019). Knowledge of SynCom's microbial functioning can help to define the best composition of multi-species bioinoculants for improving the growth and protection of crops. It could lead to developing new sustainable agricultural practices. Indeed, as plant species and plant genotypes are selecting specific microbial rhizo-microbiota thanks to root exudates (Bouffaud, Poirier, Muller, \& Moënne-Loccoz, 2014; Guyonnet et al., 2018; Haichar et al., 2008; Pérez-Jaramillo, Mendes, \& Raaijmakers, 2016), we can expect that the use of multi-species consortia or SynCom can improve the rhizosphere establishment and expression of plant-beneficial activities of at least a minimum of partners of the bio-inoculant in any environmental conditions and crop systems.

Plant metabolomics can help to better understand the mechanisms of action of PGPR consortia on plant and to identify those that best interact 
with plants. For instance, it was recently shown that a consortium of PGPR can alleviate drought stress and decrease damages to chlorophyll and photosystem (Khan et al., 2019). The consortium has the capacity to enhance the levels of soluble sugars and sugar derivatives that can act as osmoprotectants, and to reduce the lipid peroxidation and production of reactive oxygen species, by increasing the content of some amino acids to enhance the biosynthesis of proteins, vitamins like riboflavin and nicotinamide, and compounds like citrulline, glycerol, pipecolate, or $\mathrm{N}$-acetylputrescine, etc. In other studies, consortium ability to modify the content of some metabolic plant biomarkers have been looked for. Consortia comprising of one Pseudomonas strain, a mycorrhizal inoculant mix composed of three Glomus strains, and one strain of Azospirillum (i.e., three different consortia containing three different Azospirillum strains were constituted) were inoculated on maize seeds. The effects on maize were measured notably using secondary metabolic profiling and biomass measurements. All the three-component consortia have similar phytostimulation effects, despite different secondary metabolic responses (Couillerot et al., 2013; Walker et al., 2012). Maize secondary metabolite profiles varied between treatments, and especially when plants were inoculated by single PGPR and by consortia, pointing that consortium effects could not be predicted based on knowledge of single inoculation effects. In addition, maize elaborated specific metabolic patterns according to the Azospirillum strains present within the three-component consortia (Couillerot et al., 2013). Discriminant compounds involved in the separation of secondary metabolite profiles from consortium-inoculated maize plants are belonging to the family of benzoxazinoids and cinnamic acids that are involved in biotic interactions and key plant biomarkers (Zhou, Richter, \& Jander, 2018).

\section{Conclusion}

Metabolomics is a useful tool for the characterization of volatile organic compounds (VOCs) involved in plant-insect interactions, or the bioguided identification of active compounds from new raw materials. On the other hand, metabolomics approach can be used for the characterization of metabolic pathways affected by plant priming, biostimulant or elicitor application and/or for mechanistic study of Plant/PGPR interaction through biomarker specific metabolic fingerprint study. 


\section{References}

Ahmed, N., Darshanee, H. L. C., Fu, W. Y., Hu, X.-S., Fan, Y., \& Liu, T. X. (2018). Resistance of seven cabbage cultivars to green peach aphid (Hemiptera: Aphididae). Journal of Economic Entomology, 111, 909-916.

Ali, M., Sugimoto, K., Ramadan, A., \& Arimura, G. (2013). Memory of plant communications for priming anti-herbivore responses. Science Reports, 3, 1872.

Andreu, V., Levert, A., Amiot, A., Cousin, A., Aveline, N., \& Bertrand, C. (2018). Chemical composition and antifungal activity of plant extracts traditionally used in organic and biodynamic farming. Environmental Science and Pollution Research, 25, 29971-29982.

Andrić, S., Meyer, T., \& Ongena, M. (2020). Bacillus responses to plant-associated fungal and bacterial communities. Frontiers in Microbiology, 11, 1350. https://doi.org/10.3389/ fmicb.2020.01350.

Arimura, G., \& Pearse, I. S. (2017). From the lab bench to the Forest: Ecology and Defence mechanisms of volatile-mediated talking trees. Advances in Botanical Research, 82, 3-17.

Avellaneda, J., Díaz, M., Coy-Barrera, E., Rodríguez, D., \& Osorio, C. (2019). Rose volatile compounds allow the design of new control strategies for the western flower thrips (Frankliniella occidentalis). Journal of Pest Science. https://doi.org/10.1007/s10340-01901131-7.

Baldwin, I. T. (2010). Plant volatiles. Current Biololy, 20, R392-R397.

Banani, H., Olivieri, L., Santoro, K., Garibaldi, A., Gullino, M. L., \& Spadaro, D. (2018). Thyme and savory essential oil efficacy and induction of resistance against Botrytis cinerea through priming of defense responses in apple. Food, 2018(7), 11.

Bassard, J. E., Ullmann, P., Bernier, F., \& Werck-Reichhart, D. (2010). Phenolamides: Bridging polyamines to the phenolic metabolism. Phytochemistry, 71, 1808-1824.

Belimov, A. A., Kojemiakov, A. P., \& Chuvarliyeva, C. V. (1995). Interaction between barley and mixed cultures of nitrogen fixing and phosphate-solubilizing bacteria. Plant and Soil, 173, 29-37.

Beran, F., Köllner, T. G., Gershenzon, J., \& Tholl, D. (2019). Chemical convergence between plants and insects: Biosynthetic origins and functions of common secondary metabolites. New Phytologist, 223, 52-67.

Bertrand, C., \& Prigent-Combaret, C. (2012). Alternatives to pesticides. Biofutur, 330, 39-40.

Besset-Manzoni, Y., Rieusset, L., Joly, P., Comte, G., \& Prigent-Combaret, C. (2018). Exploiting rhizosphere microbial cooperation for developing sustainable agriculture strategies. Environmental Science and Pollution Research, 25, 1-18.

Bicchi, C., \& Maei, M. (2012). The plant Volatilome: Methods of analysis. In J. Normanly (Ed.), Vol. 918. High-throughput phenotyping in plants: Methods and protocols, methods in molecular biology (pp. 289-310). Totowa, NJ, USA: Humana Press.

Boiteux, J., Monardez, C., Fernández, M.Á., Espino, M., Pizzuolo, P., \& Silva, M. F. (2018). Larrea divaricata volatilome and antimicrobial activity against Monilinia fructicola. Microchemical Journal, 142, 1-8.

Bouffaud, M. L., Poirier, M. A., Muller, D., \& Moënne-Loccoz, Y. (2014). Root microbiome relates to plant host evolution in maize and other Poaceae. Environmental Microbiology, 16, 2804-2814.

Boyer, M., Bally, R., Perrotto, S., Chaintreuil, C., \& Wisniewski-Dyé, F. (2008). A quorum-quenching approach to identify quorum-sensing-regulated functions in Azospirillum lipoferum. Research in Microbiology, 159, 699-708.

Brazier-Hicks, M., Evans, K. M., Gershater, M. C., Puschmann, H., Steel, P. G., \& Edwards, R. (2009). The C-glycosylation of flavonoids in cereals. Journal of Biological Chemistry, 284, 17926-17934. 
Broeckling, C. D., Huhman, D. V., Farag, M. A., Smith, J. T., May, G. D., Mendes, P., et al. (2005). Metabolic profiling of Medicago truncatula cell cultures reveals the effects of biotic and abiotic elicitors on metabolism. Journal of Experimental Botany, 56, 323-336. https:// doi.org/10.1093/jxb/eri058.

Brown, P., \& Saa, S. (2015). Biostimulants in agriculture. Frontiers in Plant Science, 6, 671.

Burdziej, A., Da Costa, G., Gougeon, L., Le Mao, I., Bellée, A., Corio-Costet, et al. (2019). Impact of different elicitors on grapevine leaf metabolism monitored by $1 \mathrm{H}$ NMR spectroscopy. Metabolomics, 15, 67. https://doi.org/10.1007/s11306-019-1530-5.

Cassán, F., Coniglio, A., López, G., Molina, R., Nievas, S., Le Noir de Carlan, C., et al. (2020). Everything you must know about Azospirillum and its impact on agriculture and beyond. Biology and Fertility of Soils, 56, 461-479.

Chamam, A., Sanguin, H., Bellvert, F., Meiffren, G., Comte, G., Wisniewski-Dyé, F., et al. (2013). Plant secondary metabolite profiling evidences strain-dependent effect in the Azospirillum-Oryza sativa association. Phytochemistry, 87, 65-77.

Chamam, A., Wisniewski-Dyé, F., Comte, G., Bertrand, C., \& Prigent-Combaret, C. (2015). Differential responses of Oryza sativa secondary metabolism to biotic interactions with cooperative, commensal and phytopathogenic bacteria. Planta, 242(6), 1439-1452.

Combes-Meynet, E., Pothier, J. F., Moënne-Loccoz, Y., \& Prigent-Combaret, C. (2011). The Pseudomonas secondary metabolite 2,4-diacetylphloroglucinol is a signal inducing rhizoplane expression of Azospirillum genes involved in plant-growth promotion. Molecular Plant Microbe Interaction, 24, 271-284. https://doi.org/10.1094/MPMI-0710-0148.

Conchou, L., Lucas, P., Meslin, C., Proffit, M., Staudt, M., \& Renou, M. (2019). Insect Odorscapes: From plant volatiles to natural olfactory scenes. Frontiers in Physiology, 10, 972. https://doi.org/10.3389/fphys.2019.00972.

Couillerot, O., Combes-Meynet, E., Pothier, J. F., Bellvert, F., Challita, E., Poirier, M. A., et al. (2011). The role of the antimicrobial compound 2,4-diacetylphloroglucinol in the impact of biocontrol Pseudomonas fluorescens F113 on Azospirillum brasilense phytostimulators. Microbiology, 157, 1694-1705. https://doi.org/10.1099/mic.0.043943-0.

Couillerot, O., Ramírez-Trujillo, A., Walker, V., von Felten, A., Jansa, J., Maurhofer, M., et al. (2013). Comparison of prominent Azospirillum strains in Azospirillum-PseudomonasGlomus consortia for promotion of maize growth. Applied Microbiology and Biotechnology, 97, 4639-4649. https://doi.org/10.1007/s00253-012-4249-z.

Delory, B. M., Delaplace, P., Fauconnier, M. L., \& du Jardin, P. (2016). Root-emitted volatile organic compounds: Can they mediate belowground plant-plant interactions? Plant and Soil, 402, 1-26.

Deniau, M., Bonafos, R., Chovelon, M., Parvaud, C., Furet, A., Bertrand, C., et al. (2019). Willow extract (Salix cortex), a basic substance of agronomical interests. International Journal of Bio-resource and Stress Management, 10, 408-418.

Drogue, B., Doré, H., Borland, S., Wisniewski-Dyé, F., \& Prigent-Combaret, C. (2012). Which specificity in cooperation between phytostimulating rhizobacteria and plants? Research in Microbiology, 163, 500-510.

Drogue, B., Sanguin, H., Chamam, A., Mozar, M., Llauro, C., Panaud, O., et al. (2014). Plant root transcriptome profiling reveals a strain-dependent response during Azospirillum-rice cooperation. Frontiers in Plant Science, 5, 607.

El Zemrany, H., Cortet, J., Lutz, M. P., Chabert, A., Baudoin, E., Haurat, J., et al. (2006). Field survival of the phytostimulator Azospirillum lipoferum CRT1 and functional impact on maize crop, biodegradation of crop residues, and soil faunal indicators in a context of decreasing nitrogen fertilization. Soil Biology and Biochemistry, 38, 1712-1726.

Erb, M., Veyrat, N., Robert, C. A., Xu, H., Frey, M., Ton, J., et al. (2015). Indole is an essential herbivore-induced volatile priming signal in maize. Nature Communications, 6,6273 . 
European Biostimulants Industry Council. (2012). Towards an optimal regulatory framework for biostimulants. EBIC position paper, 1-7.

Füller, T. N., Bertrand, C., Antonello, B., Wesp, C., de Barros, I. B. I., \& Neto, J. F. B. (2017). Chemical diversity of wild populations of Elionurus muticus (Spreng.) and the allelopathic effect of its essential oil. Journal of Essential Oil Research, 29, 499-506. https:// doi. org/10.1080/10412905.2017.1313786.

Füller, T. N., Bertrand, C., Simon, A., de Barros, I. B. I., \& Neto, J. F. B. (2014). Elionurus muticus as an alternative source of Citral from Pampa biome, Brazil. Journal of Oleo Science, 63, 1109-1116.

Gawlik-Dziki, U., Dziki, D., Nowak, R., Świeca, M., Olech, M., \& Pietrzak, W. (2016). Influence of sprouting and elicitation on phenolic acids profile and antioxidant activity of wheat seedlings. Journal of Cereal Science, 70, 221-228. https://doi.org/10.1016/j.jcs. 2016.06.011.

Graña, E., Sotelo, T., Díaz-Tielas, C., Reigosa, M., \& Sánchez-Moreiras, A. (2013). The phytotoxic potential of the terpenoid citral on seedlings and adult plants. Weed Science, 61, 469-481. https://doi.org/10.1614/WS-D-12-00159.1.

Guyonnet, J. P., Guillemet, M., Dubost, A., Simon, L., Ortet, P., Barakat, M., et al. (2018). Plant nutrient resource use strategies shape active rhizosphere microbiota through root exudation. Frontiers in Plant Science, 9, 1662.

Haichar, F. Z., Marol, C., Berge, O., Rangel-Castro, J. I., Prosser, J. I., Balesdent, J., et al. (2008). Plant host habitat and root exudates shape soil bacterial community structure. ISME Journal, 2, 1221-1230.

Haichar, Z., Santaella, C., \& Heulin, T. (2014). Root exudates mediated interactions belowground. Soil Biology and Biochemistry, 77, 69-80.

Helletsburger, C., Dötterl, S., Ruprecht, U., \& Junker, R. R. (2017). Epiphytic bacteria alter floral scent emission. Journal of Chemical Ecololy, 43, 1073-1077.

Holopainen, J. K., \& Gershenzon, J. (2010). Multiple stress factors and the emission of plant VOCs. Trends in Plant Science, 15, 176-184. https://doi.org/10.1016/j.tplants. 2010.01.006.

Ikbal, C., \& Pavela, R. (2019). Essential oils as active ingredients of botanical insecticides against aphids. Journal of Pest Science, 92, 971-986.

Jactel, H., Birgersson, G., Andersson, S., \& Schlyter, F. (2011). Non-host volatiles mediate associational resistance to the pine processionary moth. Oecologia, 166, 703-711.

Jardine, K. J., Fernandes de Souza, F. V., Oikawa, P., Higuchi, N., Bill, M., Porrasghb, R., et al. (2017). Integration of C1 and C2 metabolism in trees. International Journal of Molecular Sciences, 18, E2045.

Jeschke, V., Gershenzon, J., \& Vassão, D. G. (2016). Insect detoxification of glucosinolates and their hydrolysis products. In S. Kopriva (Ed.), Vol. 80. Advances in botanical research (pp. 199-245). Amsterdam: Elsevier Ltd.

Jourdan, E., Ongena, M., \& Thonart, P. (2008). Molecular characteristics of the rhizobacteriatriggered plant immunity. Biotechnologie Agronomie Société Et Environnement, 12, 437-449.

Kantsa, A., Sotiropoulou, S., Vaitis, M., \& Petanidou, T. (2015). Plant Volatilome in Greece: A review on the properties, prospects, and Chemogeography. Chemistry \& Biodiversity, 12, 1466-1480.

Karban, R., Shiojiri, K., \& Ishizaki, S. (2010). An air transfer experiment confirms the role of volatile cues in communication between plants. The American Naturalist, 176, 381e384.

Khan, N., Bano, A., Rahman, M. A., Guo, J., Kang, Z., \& Babar, M. A. (2019). Comparative physiological and metabolic analysis reveals a complex mechanism involved in drought tolerance in chickpea (Cicer arietinum L.) induced by PGPR and PGRs. Scientific Reports, 9, 2097. https://doi.org/10.1038/s41598-019-38702-8.

Kim, K., Yim, W., Trivedi, P., Madhaiyan, M., Boruah, H. P. D., Islam, M. R., et al. (2010). Synergistic effects of inoculating arbuscular mycorrhizal fungi and Methylobacterium oryzae 
strains on growth and nutrient uptake of red pepper (Capsicum annuum L.). Plant and Soil, 327, 429-440. https://doi.org/10.1007/s11104-009-0072-4.

Kumar, S. (2017). Plant secondary metabolites (PSMs) of Brassicaceae and their role in plant defense against insect herbivores - A review. Journal of Applied and Natural Science, 9, 508-519.

Kuzmicheva, Y. V., Shaposhnikov, A. I., Petrova, S. N., Makarova, N. M., Tychinskaya, I. L., Puhalsky, J. V., et al. (2017). Variety specific relationships between effects of rhizobacteria on root exudation, growth and nutrient uptake of soybean. Plant and Soil, 419, 83-96.

Lade, S. B., Román, C., Cueto-Ginzo, A. I., Serrano, L., Sin, E., Achón, M. A., et al. (2018). Host-specific proteomic and growth analysis of maize and tomato seedlings inoculated with Azospirillum brasilense Sp7. Plant Physiology and Biochemistry, 129, 381-393.

Li, J., Hu, H., Mao, J., Yu, L., Stoopen, G., Wang, M., et al. (2019). Defense of pyrethrum flowers: Repelling herbivores and recruiting carnivores by producing aphid alarm pheromone. New Phytologist, 223, 1607-1620.

Liu, Y. X., Qin, Y., \& Bai, Y. (2019). Reductionist synthetic community approaches in root microbiome research. Current Opinion in Microbiology, 49, 97-102.

Maggini, V., Bandeira Reidel, R. V., De Leo, M., Mengoni, A., Gallo, E. R., Miceli, E., et al. (2019). Volatile profile of Echinacea purpurea plants after in vitro endophyte infection. Natural Product Research. https://doi.org/10.1080/14786419.2019.1579810.

Matilla, M. A., Ramos, J. L., Bakker, P. A. H. M., Doornbos, R., Badri, D. V., Vivanco, J., et al. (2010). Pseudomonas putida KT2440 causes induced systemic resistance and changes in Arabidopsis root exudation. Environmental Microbiology Report, 2, 381-388.

Mishra, R. P. N., Singh, R. K., Jaiswal, H. K., Kumar, V., \& Maurya, S. (2006). Rhizobiummediated induction of phenolics and plant growth promotion in rice (Oryza sativa L.). Current Microbiology, 52(5), 383-389.

Moco, S., Vervoort, J., Moco, S., Bino, R. J., De Vos, R. C. H., \& Bino, R. (2007). Metabolomics technologies and metabolite identification. Trends in Analytical Chemistry, $26,855-866$.

Morant, A. V., Jørgensen, K., Jørgensen, C., Paquette, S. M., Sánchez-Pérez, R., \& Møller, B. L. (2008). B-Glucosidases as detonators of plant chemical defense. Phytochemistry, 69, 1795-1813.

Moreira, X., Nell, C. S., Katsanis, A., Rasmann, S., \& Mooney, K. A. (2018). Herbivore specificity and the chemical basis of plant-Plant communication in Baccharis salicifolia (Asteraceae). New Phytologist, 220, 703-713.

Okada, K., Abe, H., \& Arimura, G. (2015). Jasmonates induce both defense responses and communication in monocotyledonous and dicotyledonous plants. Plant \& Cell Physiology, $56,16 \mathrm{e} 27$.

Osbourn, A. E., Qi, X., Townsend, B., \& Qin, B. (2003). Dissecting plant secondary metabolism-Constitutive chemical defences in cereals. New Phytologist, 159(1), 101-108.

Pagnussat, L. A., Salcedo, F., Maroniche, G., Keel, C., Valverde, C., \& Creus, C. M. (2016). Interspecific cooperation: Enhanced growth, attachment and strain-specific distribution in biofilms through Azospirillum brasilense-Pseudomonas protegens co-cultivation. FEMS Microbiology Letters, 363, fnw238. https://doi.org/10.1093/femsle/fnw238.

Pandin, C., Darsonval, M., Mayeur, C., Le Coq, D., Aymerich, S., \& Briandet, R. (2019). Biofilm formation and synthesis of antimicrobial compounds by the biocontrol agent Bacillus velezensis QST713 in an Agaricus bisporus compost micromodel. Applied in Environmental Microbiology, 85. https://doi.org/10.1128/AEM.00327-19. e00327-19.

Papanastasiou, S. A., Ioannou, C. S., \& Papadopoulos, N. T. (2020). Oviposition-deterrent effect of linalool-A compound of citrus essential oils-On female Mediterranean fruit flies, Ceratitis capitata (Diptera: Tephritidae ). Pest Management Science. https://doi.org/ $10.1002 /$ ps.5858. 
Paudel Timilsena, B., Seidl-Adams, I., \& Tumlinson, J. H. (2020). Herbivore-specific plant volatiles prime neighboring plants for nonspecific defense responses. Plant, Cell $\mathcal{E}$ Environment, 43, 787-800.

Pavela, R., \& Benelli, G. (2016). Essential oils as ecofriendly biopesticides? Challenges and constraints. Trends in Plant Science, 21, 1000-1007.

Pearse, I. S., Hughes, K., Shiojiri, K., Ishizaki, S., \& Karban, R. (2013). Interplant volatile signaling in willows: Revisiting the original talking trees. Oecologia, 172, 869e875.

Pérez-Jaramillo, J. E., Mendes, R., \& Raaijmakers, J. M. (2016). Impact of plant domestication on rhizosphere microbiome assembly and functions. Plant Molecular Biology, 90, 635-644.

Popovici, J., Bertrand, C., Comte, G., (2009). Use of a plant myrica scale for the production of an agent weedkiller. Patent. WO2010012945A2.

Popovici, J., Bertrand, C., Jacquemoud, D., Bellvert, F., Fernandez, M. P., Comte, G., et al. (2011). An allelochemical from Myrica gale with strong phytotoxic activity against highly invasive Fallopia $x$ bohemica taxa. Molecules, 16, 2323-2333.

Qiu, Y., Liu, Q., \& Beta, T. (2009). Antioxidant activity of commercial wild rice and identification of flavonoid compounds in active fractions. Journal of Agricultural and Food Chemistry, 57, 7543-7551.

Rakpenthai, A., Khaksar, G., Burow, M., Olsen, C. E., \& Sirikantaramas, S. (2019). Metabolic changes and increased levels of bioactive compounds in white radish (Raphanus sativus L. cv. 01) sprouts elicited by Oligochitosan. Agronomy, 9, 467.

Ramamoorthy, V., Viswanathan, R., Raguchander, T., Prakasam, V., \& Samiyappan, R. (2001). Induction of systemic resistance by plant growth promoting rhizobacteria in crop plants against pests and diseases. Crop Protection, 20, 1-11.

Rieusset, L., Rey, M., Muller, D., Vacheron, J., Gerin, F., Dubost, A., et al. (2020). Secondary metabolites from plant-associated Pseudomonas are overproduced in biofilm. Microbial Biotechnology, 0, 1-19. https://doi.org/10.1111/1751-7915.13598.

Rodriguez-Saona, C. R., Rodriguez-Saona, L. E., \& Frost, C. J. (2009). Herbivore-induced volatiles in the perennial shrub, Vaccinium corymbosum, and their role in inter-branch signaling. Journal of Chemical Ecology, 35, 163-175.

Rosenberg, E., \& Zilber-Rosenberg, I. (2016). Microbes drive evolution of animals and plants: The hologenome concept. MBio, 7, 1-8.

Rozier, C., Erban, A., Hamzaoui, J., Prigent-Combaret, C., Comte, G., Kopka, J., et al. (2016). Xylem sap metabolite profile changes during phytostimulation of maize by the plant growth-promoting rhizobacterium, Azospirillum lipoferum CRT1. Metabolomics (Los Angel), 6, 3.

Sarma, B. K., Yadav, S. K., Singh, S., \& Singh, H. B. (2015). Microbial consortium-mediated plant defense against phytopathogens: Readdressing for enhancing efficacy. Soil Biology and Biochemistry, 87, 25-33.

Sharifi-Rad, J., Sureda, A., Tenore, G. C., Daglia, M., Sharifi-Rad, M., Valussi, M., et al. (2017). Biological activities of essential oils: From plant Chemoecology to traditional healing systems. Molecules, 22, 70. https://doi.org/10.3390/molecules22010070.

Sharma, A., Kumar, V., Shahzad, B., Tanveer, M., Sidhu, G. P. S., Handa, N., et al. (2019). Worldwide pesticide usage and its impacts on ecosystem. SN Applied Sciences, 1, 1446.

Staudt, M., Byron, J., Piquemal, K., \& Williams, J. (2019). Compartment specific chiral pinene emissions identified in a maritime pine forest. Science of the Total Environment, 654, 1158-1166.

Takabayashi, J., \& Shiojiri, K. (2019). Multifunctionality of herbivory-induced plant volatiles in chemical communication in tritrophic interactions. Current Opinion in Insect Science, 32, 110-117.

Vacheron, J., Desbrosses, G., Bouffaud, M. L., Touraine, B., Moënne-Loccoz, Y., Muller, D., et al. (2013). Plant growth-promoting rhizobacteria and root system functioning. Frontiers in Plant Science, 4, 356. 
Valette, M., Rey, M., Gerin, F., Comte, G., \& Wisniewski-Dyé, F. (2020). A common metabolomic signature is observed upon inoculation of rice roots with various rhizobacteria. Journal of Integrative Plant Biology, 62(2), 228-246.

van Lenteren, J. C., Bolckmans, K., Köhl, J., Ravensberg, W. J., \& Urbaneja, A. (2018). Biological control using invertebrates and microorganisms: Plenty of new opportunities. Bio Control, 63, 39-59.

Vanholme, R., De Meester, B., Ralph, J., \& Boerjan, W. (2019). Lignin biosynthesis and its integration into metabolism. Current Opinion in Biotechnology, 56, 230-239.

Venturi, V., \& Keel, C. (2016). Signaling in the rhizosphere. Trends in Plant Science, 21, 187-198.

Vivaldo, G., Masi, E., Taiti, C., Caldarelli, G., \& Mancuso, S. (2017). The network of plant volatile organic compounds. Scientific Reports, 7, 11050.

Vurukonda, S. S. K., Vardharajula, S., Shrivastava, M., \& SkZ, A. (2016). Enhancement of drought stress tolerance in crops by plant growth promoting rhizobacteria. Microbiological Research, 184(supplement C), 13-24.

Walker, V., Bertrand, C., Bellvert, F., Moënne-Loccoz, Y., Bally, R., \& Comte, G. (2011). Host plant secondary metabolite profiling shows a complex, strain-dependent response of maize to plant growth-promoting rhizobacteria of the genus Azospirillum. New Phytologist, 189(2), 494-506.

Walker, V., Couillerot, O., Von Felten, A., Bellvert, F., Jansa, J., Maurhofer, M., et al. (2012). Variation of secondary metabolite levels in maize seedling roots induced by inoculation with Azospirillum, Pseudomonas and Glomus consortium under field conditions. Plant and Soil, 356, 151-163.

Walters, D. R., Ratsep, J., \& Havis, N. D. (2013). Controlling crop diseases using induced resistance: Challenges for the future. Journal of Experimental Botany, 64, 1263-1280. https://doi.org/10.1093/jxb/ert026.

Wong, Y. F., Yan, D. D., Shellie, R. A., Sciarrone, D., \& Marriott, P. J. (2019). Rapid plant volatiles screening using headspace SPME and person-portable gas chromatographymass spectrometry. Chromatographia, 82, 297-305.

Wu, S. C., Cao, Z. H., Li, Z. G., Cheung, K. C., \& Wong, M. H. (2005). Effects of biofertilizer containing $\mathrm{N}$-fixer, $\mathrm{P}$ and $\mathrm{K}$ solubilizers and $\mathrm{AM}$ fungi on maize growth: A greenhouse trial. Geoderma, 125, 155-166.

Zagrobelny, M., de Castro, E. C. P., Møller, B. L., \& Bak, S. (2018). Cyanogenesis in arthropods: From chemical warfare to nuptial gifts. Insects, 9, 51.

Zhang, P. J., Wei, J. N., Zhao, C., Zhang, Y. F., Li, C. Y., Liu, S. S., et al. (2019). Airborne host-plant manipulation by whiteflies via an inducible blend of plant volatiles. Proceedings of the National Academy of Sciences of United States of America, 116, 7387-7396.

Zhou, S., Richter, A., \& Jander, G. (2018). Beyond defense: Multiple functions of benzoxazinoids in maize metabolism. Plant and Cell Physiology, 59, 1528-1533. 